\title{
Optimizing the layout of wind turbines by upgrading a wind farm
}

\author{
Abdelouahad Bellat ${ }^{1 *}$, Khalifa Mansouri ${ }^{1}$, and Abdelhadi Raihani ${ }^{1}$ \\ ${ }^{1}$ SSDIA Laboratory, Hassan II University of Casablanca, ENSET of Mohammedia, 28830, Morocco
}

\begin{abstract}
The optimization of the size of wind farms is little studied in the literature. The objective of this study is to renew the existing wind farms by inserting new wind turbines with different characteristics. To evaluate our approach, a genetic algorithm was chosen to optimize our objective function, which aims to maximize the power of the wind farm studied at a reasonable cost, the Jensen wake model was chosen for the power calculation of the park. The results obtained from the simulation on the Horns-rev wind farm showed a significant increase in energy and a relatively reasonable cost of energy.
\end{abstract}

\section{Introduction}

The strong demand for renewable energies has pushed the designers of wind farms to redouble their efforts on the optimization of the energy produced by a wind farm, in fact wind power has become more competitive compared to other sources of energy. energy such as (solar photovoltaic and fossil fuels) [1], it is also thanks to the advantages of wind energy, such as the low emission of greenhouse gases and the cleanliness of this energy [2]. Power production by country is shown in Figure 1, it shows that China is the largest producer of wind power. However, a lot of effort is being made by the International Energy Agency [3] to meet global needs of $18 \%$ by 2050 .

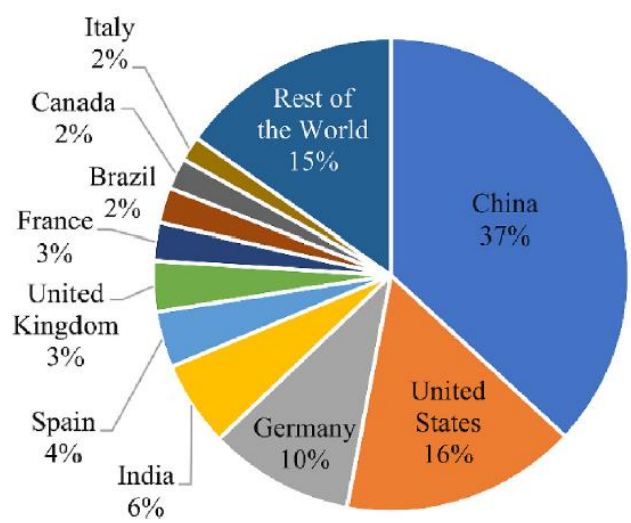

Fig. 1. Below the Wind energy produced by country [4].

Designing a wind farm generally refers to choosing an appropriate location of one wind turbine relative to the other within a limited area [5]. This choice constitutes a major challenge for designers, mainly due to the interference of wakes generated by upstream wind turbines [6-7]. The random nature of these interferences and its strong dependence on installation site variables and design parameters not only affects the performance of wind farms but of course the entire viability of the wind project [8]. Therefore, it is interesting when designing a wind farm to understand how these different variables act on the interactions between wind turbines and therefore on the quality of production performance. In addition, for a wind farm of a few wind turbines, designers warn of simple methods of listing possible configurations or attempting to find them by hand. However, these methods are no longer obvious and effective with the current trend of large wind farms and with a large number of wind turbines [9]. Faced with this problem, it is crucial to resort to other more rational methods such as heuristic optimization methods [10-11] which are particularly effective in solving this kind of problem.

Choosing one configuration among others remains a major difficulty for designers. Indeed, in real wind projects the selection of a wind farm configuration is carried out according to the requirements defined by the decision maker [12-13]. That is, the design is carried out according to the preferences of the decision-maker and the importance given to the various design objectives. At this level an important question arises on how to formalize and integrate the preferences of the decisionmaker in the process of optimizing the design of existing wind farms. A rigorous answer to this question constitutes our main contribution which consists in updating an existing wind farm by maximizing the energy and minimizing the cost of a wind farm.

Indeed, many wind farms founded in previous years have not updated in terms of optimization [14], previous studies have shown that after 20 to 25 years it is generally recommended to "repowered" or "decommissioned" them. old wind farms [15-16], the redevelopment of an existing wind farm consists of changing a few parts or even a turbine [17], in the event that the "repowered" method is delicate, the wind farm

\footnotetext{
* Corresponding author: author@email.org
} 
is decommissioned and consequently the shutdown of electricity production.

\section{Wind farm modeling}

\subsection{Wake modeling}

The wake downstream of the wind turbines is characterized by a high-speed deficit and level of turbulence which affects the performance of the wind turbines, the powers supplied are reduced and the loads on the rotors are greater [18-19], which results in the reduction of their life. life. However, there are several models which predict the energy produced from a wind farm and which takes into account the wake effect, among the most used wake models in the literature is the Jensen model [20], figure 2 shows the influence of the downstream turbine by the propagation of the wake from the upstream turbine.

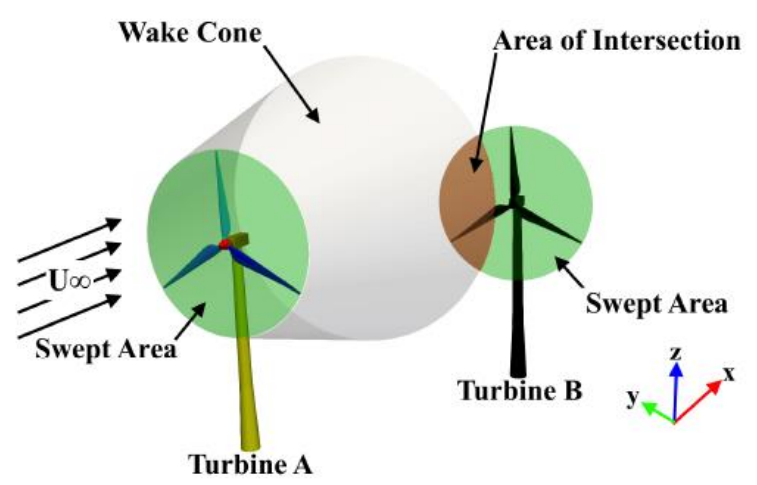

Fig. 2. influence of the downstream turbine by the propagation of the wake from the upstream turbine [21].

In the rest of this paper, we will use Jensen's model for our wind speed calculation. Therefore, the speed deficit is expressed as follows:

Where,

$$
V_{d f}=V_{f}\left[\left(1-\sqrt{1-C_{T}}\right)\left(\frac{D}{D_{\text {wake }}}\right)^{2}\right]
$$

$D$ : Rotor Diameter (m)

$D_{\text {wake }}:$ Wake diameter $(\mathrm{m})$

$C_{T}$ : Trust coefficient

$V_{f}$ : Free incoming wind speed $(\mathrm{m} / \mathrm{s})$

$V_{d f}:$ Wind velocity deficit $(\mathrm{m} / \mathrm{s})$

The variation of the wake diameter depends on the size of the rotor and on a wake minimization coefficient [22].

\subsection{Modeling of energy production}

To calculate the energy produced in a wind farm and under the wake effect, we will use the expressions established in [23], so the approximate expressions of the power of a wind turbine is as follows:

$$
P_{W T}=\frac{1}{2} \rho \pi \frac{D^{2}}{4} C_{E F}\left(V_{f}-V_{d f}\right)^{3}
$$

Where,

$C_{E F}$ is the efficiency factor that we calculate it as follows:

$$
C_{E F}=C_{p} \eta_{m} \eta_{g}
$$

The power of the wind farm $P_{W F}$ is easily deduced by adding up each wind turbine in the farm.

$$
P_{W F}=\sum_{i=1}^{N_{t}} P_{W T}
$$

Equation 5 expresses the efficiency of the wind farm:

$$
\eta_{W F}=\frac{P_{W F}}{\left(\frac{1}{2} \rho \pi \frac{D^{2}}{4} C_{E F} V_{f}^{3}\right)}
$$

The coordinates of the wind turbines are denoted by $(\mathrm{x}, \mathrm{y})$, the spacing between the wind turbines and the deficit are expressed in [24] [25], So the speed deficit calculation is expressed by equation 6 :

$$
V_{d f t}=\sqrt{\sum_{i=1}^{N_{u p}}\left(\frac{A_{O V}}{A}\right)\left(V_{d f}\right)^{2}}
$$

Where, $A_{O V}$ is the overlap area $\left(\mathrm{m}^{2}\right)$, A represents the swept area of the wind turbines $\left(\mathrm{m}^{2}\right)$, and $N_{u p}$ is the number of upstream wind turbines.

\subsection{Case study: Horns Rev 1 Wind Farm}

The Horns-rev1 [26-27] wind farm is located in the North Sea $14 \mathrm{~km}$ from the west coast of Denmark and covers an area of approximately $20 \mathrm{~km} 2$. It is composed of 80 Vestas type wind turbines with a rotor diameter equal to 80 , a height of $70 \mathrm{~m}$ and a nominal power of 2 MW. The wind turbines are placed in a regular arrangement of 8 rows and 10 columns with the interdistance between the wind turbines equal to 7 times the diameter of the rotor for a wind direction equal to $0^{\circ}$ as shown in Figure 3.

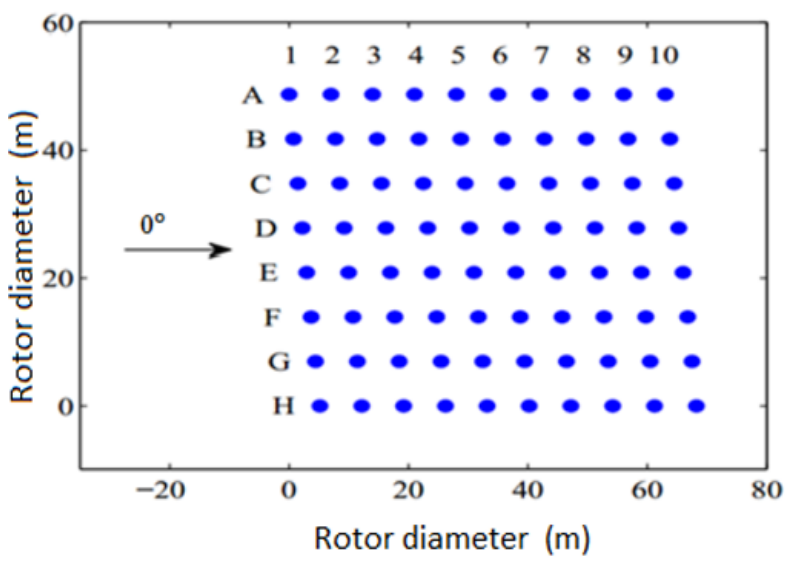

Fig. 3. Presentation of the Horns-rev 1 marine wind farm [28]. 


\section{Methodology}

\subsection{Objective function}

The aim of the studied objective function is to maximize the power and minimize the cost of a wind farm.

Indeed, to achieve the expectations of the objective function, we will try to update the wind farm studied by installing new wind turbines outside or inside a wind farm while respecting the constraints related to the wind farm. area of the wind farm and the cost of installation.

The objective function is defined by the equation 7 .

$$
\text { FOBJ }=\max \frac{P_{\text {total }}}{\text { Cost }}
$$

The cost is expressed as a function of the number of wind turbines $(\mathrm{N})$ installed in the equation 8 .

$$
\text { Cost }=\mathrm{N}\left[\frac{2}{3}+\frac{1}{3} \mathrm{e}^{-0.00174 \mathrm{~N}^{2}}\right]
$$

in this study we will adopt the simplified cost model [28] and we will use the equation 10 which expresses Total Cost Index,TCI.

$$
\text { TCI }=323 \text { UCI }
$$

Where $U C I$ is Unit Cost Index [29]

\subsection{Optimization algorithm}

Many studies have shown that genetic algorithms (GA) are very effective in solving optimization problems [30] hence the use of (GA) in the optimization of wind farms even if they are expensive in his calculations.

The 5 steps of a genetic algorithm are noted below:

- Build an initial population of $\mathrm{N}$ solutions.

- Evaluate each of the individuals in the population.

- Generate new solutions by selecting parents in proportion to their assessment. Apply the crossing and mutation operators during breeding.

- When $\mathrm{N}$ new individuals have been generated, they then replace the old population. The individuals of the new population are evaluated in turn.

- If the allotted time has not been exceeded (or the maximum number of generations has not been reached), go back to step 3 .

The flowchart in figure 4 shows the optimization procedure by the objective function defined previously

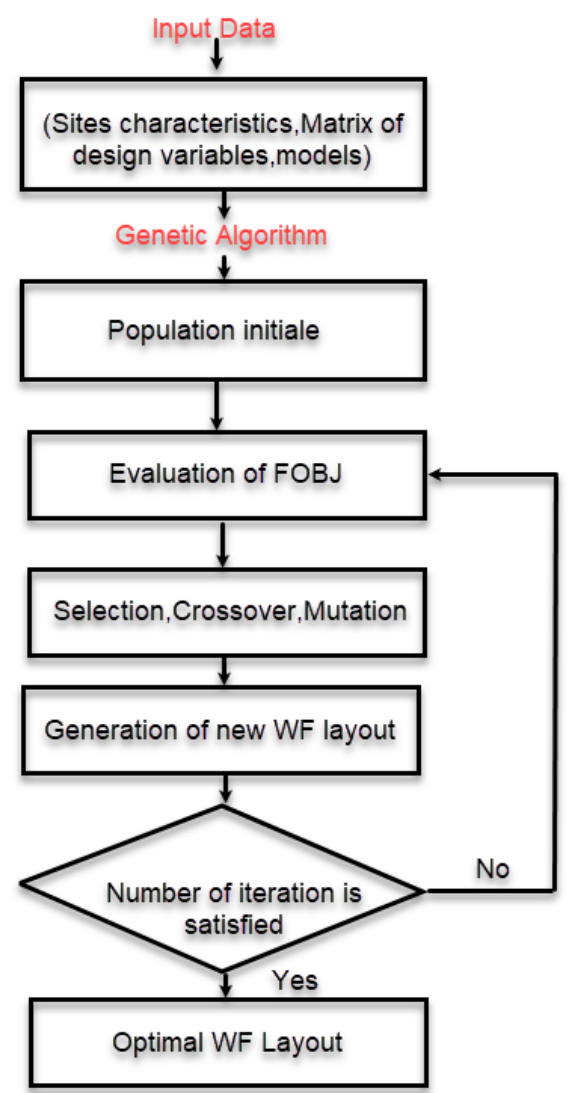

Fig. 4. Presentation Genetic algorithm steps [31].

The selection of turbines is limited to the same models of turbines existing in the studied wind farm (Vestas), the 19 turbines chosen have a power between

\begin{tabular}{|c|c|c|c|c|c|c|c|}
\hline $\begin{array}{c}\text { Turbine } \\
\text { Code }\end{array}$ & 1 & 2 & 3 & 4 & 5 & 6 & 7 \\
\hline $\begin{array}{l}\text { Rated Power } \\
(\mathrm{Kw})\end{array}$ & $\begin{array}{c}181 \\
5\end{array}$ & $\begin{array}{c}181 \\
5\end{array}$ & $\begin{array}{c}200 \\
0\end{array}$ & $\begin{array}{c}200 \\
0\end{array}$ & $\begin{array}{c}200 \\
0\end{array}$ & $\begin{array}{c}200 \\
0\end{array}$ & $\begin{array}{c}260 \\
0\end{array}$ \\
\hline $\begin{array}{l}\text { Rotor } \\
\text { Diameter(m) }\end{array}$ & 90 & 100 & 80 & 90 & 100 & 110 & 100 \\
\hline $\begin{array}{l}\text { Rated Speed } \\
(\mathrm{m} / \mathrm{s})\end{array}$ & 13 & 11.5 & 14 & 13 & 12 & 11 & 15 \\
\hline $\begin{array}{l}\text { Turbine } \\
\text { Code }\end{array}$ & 8 & 9 & 10 & 11 & 12 & 13 & 14 \\
\hline $\begin{array}{l}\text { Rated Power } \\
(\mathrm{Kw})\end{array}$ & $\begin{array}{c}300 \\
0\end{array}$ & $\begin{array}{c}300 \\
0\end{array}$ & $\begin{array}{c}300 \\
0\end{array}$ & $\begin{array}{c}307 \\
5\end{array}$ & $\begin{array}{c}330 \\
0\end{array}$ & $\begin{array}{c}330 \\
0\end{array}$ & $\begin{array}{c}330 \\
0\end{array}$ \\
\hline $\begin{array}{l}\text { Rotor } \\
\text { Diameter(m) }\end{array}$ & 90 & 112 & 126 & 112 & 105 & 112 & 117 \\
\hline $\begin{array}{l}\text { Rated Speed } \\
(\mathrm{m} / \mathrm{s})\end{array}$ & 16 & 12 & 10.5 & 13 & 13.5 & 12.5 & 13 \\
\hline $\begin{array}{l}\text { Turbine } \\
\text { Code }\end{array}$ & 15 & 16 & 17 & 18 & 19 & & \\
\hline $\begin{array}{l}\text { Rated Power } \\
(\mathrm{Kw})\end{array}$ & $\begin{array}{c}345 \\
0\end{array}$ & $\begin{array}{c}345 \\
0\end{array}$ & $\begin{array}{c}345 \\
0\end{array}$ & $\begin{array}{c}345 \\
0\end{array}$ & $\begin{array}{c}345 \\
0\end{array}$ & & \\
\hline $\begin{array}{l}\text { Rotor } \\
\text { Diameter }(\mathrm{m})\end{array}$ & 105 & 112 & 117 & 126 & 136 & & \\
\hline $\begin{array}{c}\text { Rated Speed } \\
(\mathrm{m} / \mathrm{s})\end{array}$ & 13.5 & 12.5 & 11.5 & 11.5 & 11 & & \\
\hline
\end{tabular}
1.8 and $3.45 \mathrm{MW}$ and diameter between 80 and $136 \mathrm{~m}$.

Table 1. Turbine data used in the optimization. 
The Table 1 gives the code, the diameter of the rotor, the nominal speed and the nominal power.

\section{Results and discussion}

To evaluate our approach, two wind farm upgrade proposals were tested, figure 5 and figure 6 respectively show these two proposals with the addition of a new turbine internally and externally, including the objective and to maximize the exploitation of the land and minimizing the cost of the infrastructure. the existing turbines are numbered from 1 to 80 while the others are numbered from 81 .

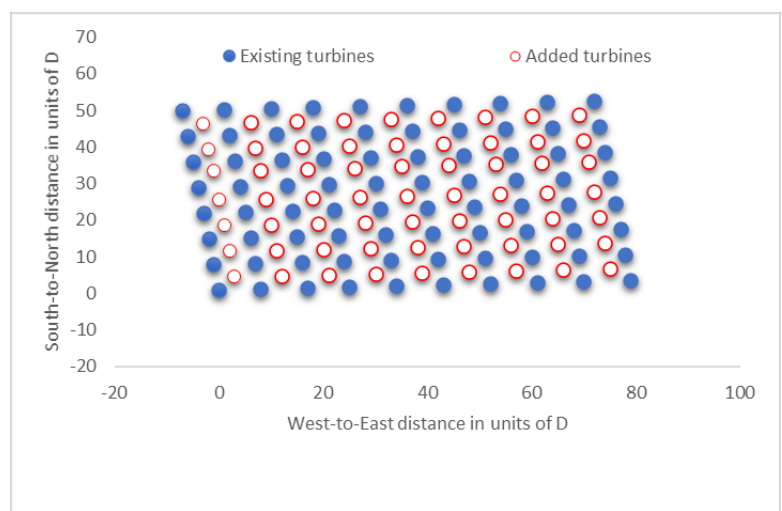

Fig. 5. Internal upgrade proposal.

To respect a minimum distance of $(3.5 \mathrm{D}$ where $\mathrm{D}$ is the turbine diameter) between the turbines, the number of turbines added internally is 63 while externally equal to 40 and they all take on the red color.

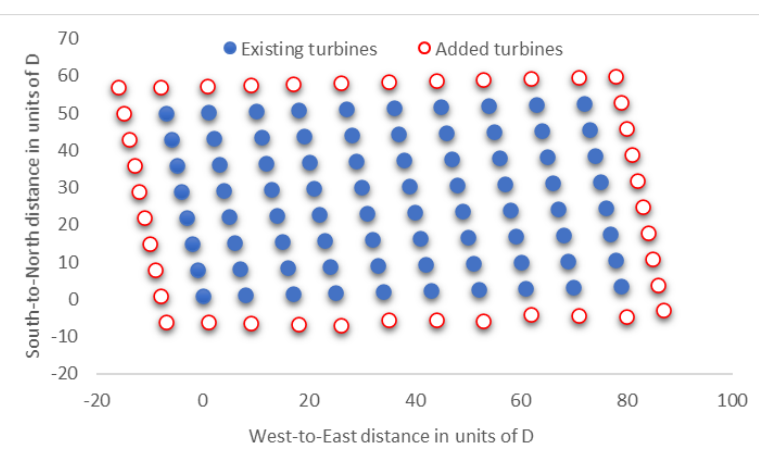

Fig. 6. External upgrade proposal.

The annual energy production (AEP) of each wind turbine is shown in figure 7, the equation 11 gives the expression to calculate this annual energy.

$$
A E P=8766 \sum_{\theta=0}^{360} \sum_{\vartheta=4}^{25} f_{(\theta, \vartheta)} P_{W T(\theta, \vartheta)}
$$

Where $f$ is the frequency of occurrence of a particular freestream speed at particular direction.

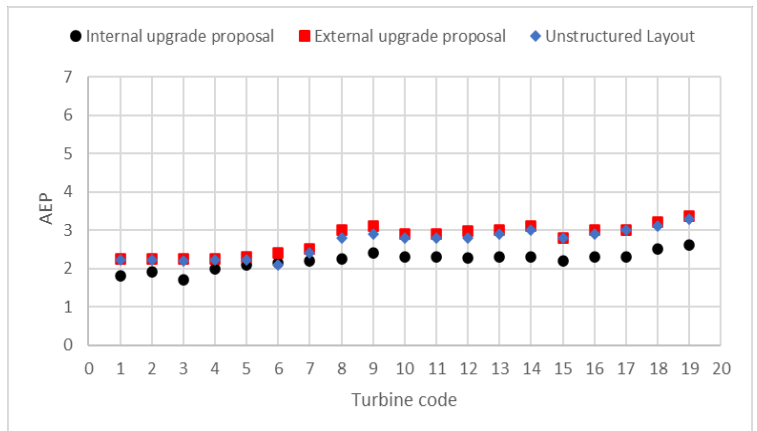

Fig. 7. Annual energy production for each turbine by the studied objective function.

The results of figure 7 and figure 8 show a compromise between the annual production of energy and the cost, however in the internal proposal of turbines the AEP varies between 1.95 and 2.70, moreover the cost varies according to the type of turbine between 1.40 to 2.85 .

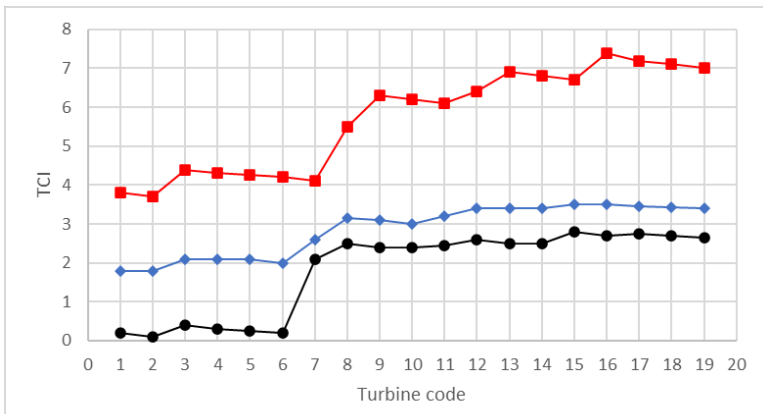

Fig. 8. Normalized total cost index

On the other hand, the external openings with only one type of turbine have an AEP value varying between 2.21 to 3.31 and with regard to the TCI the values vary between 3.85 and 7.4 .

Small wind turbines are ideal for internal upgrades with a relatively reasonable cost and higher AEP, on the other hand large wind turbines increase the cost of energy production.

The increase of the AEP in the case of the external update is accompanied by the increase of the cost, this is explained by the added area which presents an important rate in the calculation of the cost.

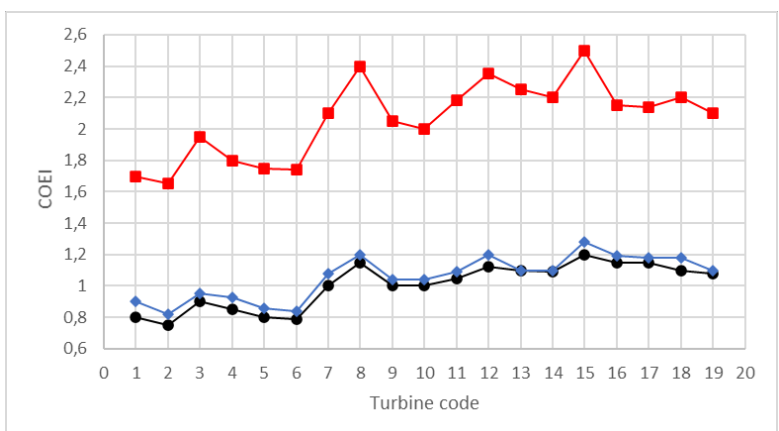

Fig. 9. Normalized cost of energy index. 
From figure 9 we notice that the internal updates are close to unity, this is explained by an increase in AEP in accordance with the TCI.

\section{Conclusions}

In this article we tried to make a study of the leveling of wind farms and to evaluate the objective function which aims at maximizing energy and minimizing the cost.

Two approaches have been adopted, the first is the addition of the turbines internally and the second is the addition of the turbines externally.

The results showed that the two approaches are interesting in terms of annual energy production, on the other hand the cost is relatively high in updating externally than interna.

\section{References}

1. IRENA. Renewable Power Generation Costs in 2017; International Renewable Energy Agency: Abu Dhabi, UAE,2018.Availableonline:https://www.irena.org//med ia/Files/IRENA/Agency/Publication/2018/Jan/IRENA 2017_Power_Costs_2018.pdf (accessed on 3 March 2019).

2. Global Wind Statistics 2017. Global Wind Energy Council (GWEC), February 2018. Available online: http:/gwec.net/wpcontent/uploads/vip/GWEC PRstats 2017 EN-003_FINAL.pdf (accessed on 3 March2019). 3. World Energy Perspectives 2016. EXECUTIVE SUMMARY.World Energy Council. Available online: https://www.worldenergy.org/wpcontent/uploads/2016/ 09/Resilience_Managing-cyber-risks_Exesummary.pdf (accessed on3March 2019).

4. The shift Project Data Portal. Available online: http://www.tsp-data-portal.org/all-datasets (accessed on 3 March 2019).

5. BP Statistical Review ofWorld Energy. June 2017. Availableonline:https://www.bp.com/content/dam/bpco untry/de_ch/PDF/bp-statistical-review-of-worldenergy2017-full-report.pdf (accessed on 3 March 2019).

6. Environmental Impacts of Wind Power. Available online:https://www.ucsusa.org/cleanenergy/renewablee nergy/environmental-impacts-wind-power (accessed on 3 March 2019).

7. Mosetti, G.; Poloni, C.; Diviacco, B. Optimization of wind turbine positioning in large wind farms by means of a genetic algorithm. J. Wind Eng. Ind. Aerodyn. 1994, 51, 105-116. [CrossRef]

8. 2014 Wind Technologies Market Report; US Department of Energy, Wind and Water Power Technologies O_ce: Berkeley, CA, USA, 2015.

9. Lindvig, K. The installation and servicing of o_shore wind farms. In European Forum for Renewable Energy Sources; A2SEA A/S: Fredericia, Denmark, 2010.

10. Saraswati, N.; Stehly, T.; Dewan, A.; Delmarre, A. Operation and Maintenance Map of U.S. O_shore Wind Farms;
ECN-E-17-028. The Netherlands, November 2017. Availableonline:https://publicaties.ecn.nl/PdfFetch.asp x?nr=ECN-E--17-028 (accessed on 3 March 2019).

11. Wind Farm Lifecycle. Available online: https://canwea.ca/communities/planning-a-wind-farm/ (accessed on3 March 2019).

12. Hou, P.; Enevoldsen, P.; Hu,W.; Chen, C.; Chen, Z. O_shore wind farm repowering optimization. Appl. Energy2017, 208, 834-844. [CrossRef]

13. Topham, E.; McMillan, D. Sustainable decommissioning of an o_shore wind farm. Renew. Energy 2017,102, 470-480. [CrossRef]

14. Sommer, A.; Hansen, K. Wind Resources at Horns Rev; Technical Report, Report No. D-160949; TechWise A/S:Fredericia, Denmark, December 2002; p. 69. 15. Jensen, L.; Mørch, C.; Sørensen, P.; Svendsen, K.H. Wake Measurements from the Horns Rev Wind Farm; EWEC:London, UK, 2004; pp. 22-25.

16. Overview of the Energy Sector. Available online: https://ens.dk/en/our-services/statistics-data-keyfiguresand-energy-maps/overview-energy-sector (accessed on 3 March 2019).

17. Barthelmie, R.; Hansen, K.; Frandsen, S.; Rathmann, O.; Schepers, J.; Schlez, W.; Phillips, J.; Rados, K.;Zervos, A.; Politis, E.; et al. Modelling and measuring flow and wind turbine wakes in large wind farmso_shore. Wind Energy 2009, 12, 431-444. [CrossRef]

18. Rathmann, O.; Barthelmie, R.; Frandsen, S. Wind turbine wake model for wind farm power production.

In Proceedings of the EuropeanWind Energy Conference, Athens, Greece, 27 February-2 March 2006.

19. Barthelmie, R.; Pryor, S.; Frandsen, S.; Hansen, K.; Schepers, J.; Rados, K.; Schlez, W.; Neubert, A.; Jensen, L.;Neckelmann, S. Quantifying the impact of wind turbine wakes on power output at o_shore wind farms.J. Atmos. Ocean. Technol. 2010, 27, 1302-1317. [CrossRef]

20. Frandsen, S.; Barthelmie, R.; Pryor, S.; Rathmann, O.; Larsen, S.; Højstrup, J.; Thøgersen, M. Analytical modelling of wind speed deficit in large o_shore wind farms. Wind Energy 2006, 9, 39-53. [CrossRef]

21. Frandsen, S.; Rathmann, O.; Barthelmie, R.; Jørgensen, H.; Badger, J.; Hansen, K.; Ott, S.; Rethore, P.; Larsen, S.;Jensen, L. The making of a secondgeneration wind farm e_ciency model complex. Wind Energy 2009, 12, 445-458. [CrossRef]

22. Beaucage, P.; Robinson, N.; Brower, M.; Alonge, C. Overview of six commercial and research wake models for large o_shore wind farms. In Proceedings of the European Wind Energy Conference \& Exhibition; European Wind Energy Association (EWEA 2012), Copenhagen, Denmark, 16-19 April 2012.

23. Rivas, R.; Clausen, J.; Hansen, K.; Jensen, L. Solving the turbine positioning problem for large o_shore windfarms by simulated annealing. Wind Eng. 2009, 33, 287-297. [CrossRef]

24. Vezyris, C. O_shore Wind Farm Optimization Investigation of Unconventional and Random Layouts. Master's Thesis, TU Delft, Delft, The Netherlands, 2012. 
25. Park, J.; Law, K. Layout optimization for maximizing wind farm power production using sequential convex programming. Appl. Energy 2015, 151, 320-334. [CrossRef]

26. Abdulrahman, M.; Wood, D. Investigating the power-COE trade-off for wind farm layout optimization considering commercial turbine selection and hub height variation. Renew. Energy 2017, 102, 267-516. [CrossRef]

27. Feng, J.; Shen, W.Z. Modelling wind for wind farm layout optimization using joint distribution of wind speed and wind direction. Energies 2015, 8, 3075-3092. [CrossRef]

28. Herbert-Acero, J.-F.; Franco-Acevedo, J.-R.; Valenzuela-Rendon, M.; Probst-Oleszewski, O. Linear wind farm layout optimization through computational intelligence. In Proceedings of the 8th Mexican International Conference on Artificial Intelligence, Guanajuato, Mexico, 9-13 November 2009; pp. 692703.

29. Tesauro, A.; Réthoré, P.-E.; Larsen, G. State of the art of wind farm optimization. In Proceedings of the European Wind Energy Conference \& Exhibition; European Wind Energy Association (EWEA 2012),

Copenhagen, Denmark, 16-19 April 2012.

30. Chowdhury, S.; Zhang, J.; Messac, A.; Castillo, L. Optimizing the arrangement and the selection of turbines for wind farms subject to varying wind conditions. Renew. Energy 2013, 52, 273-282. [CrossRef]

31. Chen, Y.; Li, H.; Jin, K.; Song, Q. Wind farm layout optimization using genetic algorithm with di_erent hub height wind turbines. Energy Convers. Manag. 2013, 70, 56-65. [CrossRef] 